\title{
Spitting cobra (Naja nigricincta nigricincta) bites complicated by rhabdomyolysis, possible intravascular haemolysis, and coagulopathy
}

\author{
E L Saaiman, ${ }^{1} \mathrm{MB} \mathrm{ChB}, \mathrm{MMed}$ (Anaesth); P J C Buys, ${ }^{2} \mathrm{MB}$ ChB, MMed (ORL) \\ ${ }^{1}$ Anaesthetist, Private Practice, Windhoek, Namibia; Member of the Namibian Snakebite Interest Group \\ ${ }^{2}$ Ear, Nose and Throat Surgeon, Private practice, Windhoek, Namibia; Namibian snakebite management expert; Founding member and head of \\ the Namibian Snakebite Interest Group
}

Corresponding author: E L Saaiman (estasaaiman@gmail.com)

\begin{abstract}
Zebra snake (Naja nigricincta nigricincta) bite is a significant health problem in Namibia. Although fatalities are thought to be rare, the severe cytotoxic effects and debilitating consequences of neglected bites are well documented. The focus of our treatment has always been the urgent treatment of necrosis. Although there have been a few reports of infant fatalities, acute renal failure and mild coagulation problems, systemic effects after envenomation were not well documented. Three case reports of patients with rhabdomyolysis, intravascular haemolysis and coagulopathy following $N$. n. nigricincta bites are presented.
\end{abstract}

S Afr Med J 2019;109(10):736-740. https://doi.org/10.7196/SAMJ.2019.v109i10.14103

The World Health Organization added snakebite to the list of Neglected Tropical Diseases in 2009. Each year, snakebite affects the lives of around 4.5 million people worldwide, seriously injuring 2.7 million men, women and children, and claiming some 125000 lives. ${ }^{[1]}$

Namibia is one of the most sparsely populated countries in the world (population 2.5 million) and home to an abundance of wildlife, including snakes. ${ }^{[2]}$ There is no official database on snakebite in Namibia. The Namibian Snakebite Interest Group (NSIG) is involved with $\sim 10$ - 20 zebra snake (Naja nigricincta nigricincta) envenomations annually (PJCB and ELS, members of NSIG, personal communication; Francois Theart, official snake rescue and antipoaching agent, personal communication).

N. n. nigricincta is a spitting cobra and is frequently encountered in Namibia. The distribution is mainly the central and northern regions of this country, and southern Angola. ${ }^{[3]}$ The snake seems to be well adapted to populated areas, and it appears to lack any fear of humans. ${ }^{[4]}$

As a result of 43 years of clinical involvement with snakebites in Namibia and clinical management of $\sim 700$ zebra snake bites, PJCB makes the following statements (personal communication): 'This spitting cobra has come to be particularly feared, especially by the rural communities, as the snake is nocturnal and commonly found inside dwellings in search of small rodents for prey. The majority of $N$. n. nigricincta bites have occurred at night while the victims were asleep. Although rarely fatal, the venom is highly cytotoxic with no neurotoxic symptoms or signs observed. ${ }^{\left[{ }^{[5]}\right.}$ Antivenom seems to be ineffective in the treatment of envenomation. Without early, adequate, speedy surgical debridement, necrosis with extensive tissue loss, contractures, disfigurement and loss of function will almost always be the outcome. The only exception being bites in the face or genital areas, where a more conservative surgical approach seems merited.'

No clinical research on $N$. n. nigricincta bites has been done. Treatment in Namibia has been derived from the clinical experience mentioned above. It was supported by studies by Warrell et al. ${ }^{[6]}$ on bites by $N$. nigricollis, a very close relative of $N$. nigricincta found in central Africa, with a remarkably similar symptom complex and outcome. ${ }^{[6]}$

The Namibian experience and treatment stand in contrast with case studies done on N. mossambica. ${ }^{[7,8]}$ This spitting cobra is found in the more tropical regions of southern Africa, northern Namibia and southern Angola. ${ }^{[9]}$ Although envenomation causes severe tissue necrosis with occasional drowsiness and respiratory depression, antivenom seems to be effective if given shortly after the bite, and delayed surgical intervention is advocated. ${ }^{[7,8]}$ The venom of N. mossambica is used in the production of our currently available polyvalent antivenom from South African Vaccine Producers $(\mathrm{SAVP}),{ }^{[10]}$ which may explain why the antivenom, given early, results in less necrosis. The venom of $N$. n. nigricincta is not used in the manufacturing of the South African Institute for Medical Research (SAIMR) polyvalent antivenom. ${ }^{[10]}$

The severe cytotoxic effects and debilitating consequences of neglected bites of the zebra snake, as well as the lack of obvious systemic involvement in the majority of patients, have resulted in emphasis being placed on urgent treatment of the necrosis. However, over the years there have been a few marring reports of unexplained infant fatalities and renal failure following $N$. n. nigricinta bites. ${ }^{[1,12]}$

The authors have started renewed research on snakebites in Namibia, with the emphasis on $N$. $n$. nigricinta bites. The objective of this research is to establish evidence-based treatment protocols for all Namibian snakebites, especially those inflicted by $N$. $n$. nigricinta, and to compile a national snakebite database. During this research three patients were encountered who showed evidence of intravascular haemolysis, rhabdomyolysis and coagulopathy as well as severe tissue necrosis.

\section{Case studies}

Case 1

At $00 \mathrm{~h} 30$ a zebra snake (N. n. nigricinta) bit a 23 -year-old man in the face. He was asleep in his bed while staying at a lodge near 
Etosha National Park. The patient was referred to the local snakebite specialist in Windhoek, where he arrived 7.5 hours after being bitten.

On admission he exhibited periorbital oedema, noticeably more severe on the right. Two fang marks, medial and inferior to the right eye with discoloration of the skin surrounding the fang marks and the upper eyelid, were noted. He complained of severe muscle pains in his back and legs.

On examination his vision and eye movements were normal. He was awake and orientated and showed no signs of muscle weakness, respiratory distress or cardiovascular compromise. Because he was stable, he was admitted to a general ward under the care of a general surgeon for initial conservative treatment and observation.

Laboratory results on day 1 were as follows: white blood cell count $(\mathrm{WBC}) 19.7 \times 10^{9} / \mathrm{L}$ (neutrophil count $17.2 \times 10^{9} / \mathrm{L}$ ). The haemoglobin concentration $(\mathrm{Hb})$ and urea and electrolytes (U\&E) were normal. Unconjugated bilirubin was increased $(57 \mu \mathrm{mol} / \mathrm{L})$, with raised lactate dehydrogenase (LDH) (1 $510 \mathrm{U} / \mathrm{L})$, aspartate transaminase (AST) $(675 \mathrm{U} / \mathrm{L})$ and alanine transaminase (ALT) (86 U/L). Dipstick urinalysis showed 2+ blood in the urine.

On the second day a creatine kinase (CK) level was requested, which was elevated (96900 U/L). LDH, AST and ALT were still high. Urine myoglobin and urine bilirubin were positive. Serum haptoglobin was very low $(0.06 \mathrm{~g} / \mathrm{L})$ (normal $0.34-2.00 \mathrm{~g} / \mathrm{L})$.

The patient was treated with aggressive fluid management, analgesics and moxifloxacin (started on day 5). Although it is controversial, we give prophylactic antibiotics to all victims of cytotoxic snakebites. Studies in Taiwan and China underlined our clinical experience of a high incidence of secondary wound infections following cytotoxic bites, especially N. n. nigricincta bites, when no antivenom is given. ${ }^{[13-17]}$

The CK values peaked on day 3 (101 $200 \mathrm{U} / \mathrm{L})$ and gradually subsided over the following days. The international normalised ratio (INR), which peaked on day 2 (1.7), normalised without specific treatment. LDH peaked on day 3 (3 $510 \mathrm{U} / \mathrm{L})$. Hb decreased from $16.3 \mathrm{~g} / \mathrm{dL}$ (day 1) to $14.1 \mathrm{~g} / \mathrm{dL}$ (day 7). The cumulative report is shown in Table 1.

Kidney function and electrolyte values stayed within normal limits.

On day 9 the patient underwent surgical debridement by a plastic surgeon. Necrotic tissue was removed under the left eye and from the left upper eyelid. He recovered fully, underwent several more debridements, and had a skin graft on day 20.

\section{Case 2}

A 7-year-old boy was bitten on the face by a zebra snake, which also spat in his eyes, at $01 \mathrm{~h} 30$ while asleep in his bed. He and his family were on holiday in Namibia, staying at a lodge in the northwestern part of the country. He was immediately taken to the local clinic, where his eyes were thoroughly rinsed with saline and where he erroneously received $10 \mathrm{~mL}$ SAVP polyvalent antivenom intravenously.

The patient was transferred to Windhoek, where he was admitted at $\sim 11 \mathrm{~h} 00$ under the care of the local snakebite expert. The bite was in the left infraorbital region, and severe bilateral periorbital oedema was present: he could not open his eyes. The swelling extended to the left side of the face and neck, with a $2 \times 3.5 \mathrm{~cm}$ blue discoloured area of skin around the bite. He was fully awake and well orientated, but extremely irritable and complaining of severe muscle pains involving his entire body. His blood pressure, pulse rate, oxygen saturation and temperature were all within normal limits. There was no evidence of muscle weakness, but he exhibited signs of hyperaesthesia. Both lungs aerated well and there was no stridor or respiratory distress. An ophthalmologist was consulted.

Owing to concern of possible airway obstruction as a result of the severe swelling of the face and neck, the patient was transferred for observation to the intensive care unit (ICU). He was treated with maintenance intravenous fluids, amoxicillin-clavulanic acid, tilidine, paracetamol, diclofenac and dexamethasone. Blood samples for a full blood count, U\&E, liver function tests (LFTs), CK and a clotting profile were sent to the laboratory, and dipstick urinalysis was requested.

Approximately 15 hours after having been bitten, the patient suddenly developed a sinus tachycardia (180 bpm), followed by a tonic-clonic convulsion. The convulsion lasted 5 minutes and terminated spontaneously. The patient was lethargic immediately after the convulsion, with increased peripheral reflexes and neck stiffness. An urgent CT scan showed no intracranial bleeding or structural abnormalities. At this stage a physician was consulted to join the team of specialists managing the patient. Intravenous sodium valproate was initiated. No further convulsions occurred and the tachycardia subsided spontaneously over the next hour.

Abnormal results of initial special investigations were as follows: dipstick urinalysis $3+$ positive for blood, WBC $31.4 \times 10^{9} / \mathrm{L}$ (neutrophil count $25.4 \times 10^{9} / \mathrm{L}$ ), INR 1.5 (normal 0.9 - 1.3), CK $2090 \mathrm{U} / \mathrm{L}$, AST $118 \mathrm{U} / \mathrm{L}$, unconjugated bilirubin $73 \mu \mathrm{mol} / \mathrm{L}$ and LD $793 \mathrm{U} / \mathrm{L}$.

Table 1. Laboratory results, patient 1

\begin{tabular}{|c|c|c|c|c|c|c|}
\hline Normal values & Day 1 & Day 2 & Day 3 & Day 4 & Day 7 & Day 9 \\
\hline $\mathrm{Hb}(13-18 \mathrm{~g} / \mathrm{dL}$ & 16.3 & 15.3 & 14.7 & - & 14.1 & - \\
\hline WBC $\left(4-11 \times 10^{9} / \mathrm{L}\right)$ & 19.7 & 22.6 & - & - & 17.7 & - \\
\hline Neutrophils $\left(2.75 \times 10^{9} / \mathrm{L}\right)$ & 17.2 & 19.5 & - & - & 11.7 & - \\
\hline $\operatorname{PLT}\left(140-420 \times 10^{9} / \mathrm{L}\right)$ & 191 & 212 & 194 & - & 337 & - \\
\hline INR $(0.9-1.3)$ & - & 1.7 & - & - & - & - \\
\hline PT (10.2 - $13.2 \mathrm{~s})$ & - & 18.2 & - & - & - & - \\
\hline PTT (25.4 - $38.4 \mathrm{~s})$ & - & 26.6 & - & - & - & - \\
\hline Unconjugated bilirubin $(2-17 \mu \mathrm{mol} / \mathrm{L})$ & 57 & - & 25 & - & - & - \\
\hline ALT (0 - $55 \mathrm{U} / \mathrm{L})$ & 86 & - & 301 & 316 & - & - \\
\hline AST (5 - $34 \mathrm{U} / \mathrm{L})$ & 675 & - & - & - & - & - \\
\hline LDH (125 - $243 \mathrm{U} / \mathrm{L})$ & 1510 & - & 3510 & 2260 & - & - \\
\hline CK $(30-200 \mathrm{U} / \mathrm{L})$ & - & 96906 & 101200 & 76200 & 4060 & 850 \\
\hline
\end{tabular}


The patient was kept in the ICU for monitoring of his vital signs. Intravenous fluids were pushed to maintain a urinary output of $2 \mathrm{~mL} /$ $\mathrm{kg} / \mathrm{h}$. Vitamin $\mathrm{K}$ and fresh-frozen plasma were given preoperatively on day 2 and clindamycin was added. Daily special investigations (FBC, U\&E, LFTs, CK and clotting profile) were done until the patient stabilised.

CK values increased until day 3 with a peak of $17360 \mathrm{U} / \mathrm{L}$. The INR peaked on day $2(1.8)$ and the WBC decreased from $31.4 \times 10^{9} / \mathrm{L}$ on admission to $11.9 \times 10^{9} / \mathrm{L}$ on day 6 .

$\mathrm{Hb}$ decreased from $15.1 \mathrm{~g} / \mathrm{dL}$ on admission to $11.9 \mathrm{~g} / \mathrm{dL}$ on day 7 . Kidney function and electrolyte values stayed within normal limits. Cumulative results are shown in Table 2.

On day 3 a plastic surgeon performed debridement of all discernible necrotic tissue. Ophthalmological examination under anaesthesia revealed no injury to the left eye but a possible completely healed corneal lesion on the right, probably caused by the venom that had been spat into the eye. A further debridement with insertion of a Crawford tube into the left lacrimal duct was done on day 5. Spreading of the necrosis necessitated additional debridement on days 7 and 9. Swelling of the neck and face only started to resolve after day 5 .

On day 10 the patient's condition was considered stable and he was transferred to the care of a plastic surgeon in South Africa, where he had several more debridements and a skin graft.

\section{Case 3}

A 20-month-old baby was bitten on the left occiput by a zebra snake at $06 \mathrm{~h} 00$ while sleeping on the floor at home, $15 \mathrm{~km}$ outside Okahandja, a small town $71 \mathrm{~km}$ north of Windhoek. The snake (a $1.4 \mathrm{~m}$ juvenile male) was killed and brought along for identification. Prior to transfer to Windhoek, the patient erroneously received 2 ampoules of SAIMR polyvalent antivenom at the local hospital.

The patient, irritable and with a raised pulse and blood pressure, arrived in Windhoek 10 hours after being bitten. The bite area was moderately swollen with blue discoloration. After being admitted under the care of a pediatrician in the ICU, an emergency debridement was done $\sim 11$ hours after the bite.

Initial blood results showed a low $\mathrm{Hb}(9.6 \mathrm{~g} / \mathrm{dL})$, a raised $\mathrm{WBC}$ $\left(18.2 \times 10^{9} / \mathrm{L}\right)$ and neutrophilia $\left(16.2 \times 10^{9} / \mathrm{L}\right)$. AST, ALT and LDH were elevated. Serum myoglobin was raised and the INR was 1.4 . A peripheral blood smear revealed polychromasia, burr cells and aniso-poikilocytosis (CK was not done on admission).

On day 2 the patient became drowsy, urine output dropped to $<1 \mathrm{~mL} / \mathrm{kg} / \mathrm{h}$, and the serum urea level increased to $8.6 \mathrm{mmol} / \mathrm{L}$ (normal $2.9-8.2 \mathrm{mmol} / \mathrm{L}$ ). This occurred in spite of aggressive fluid management. Furosemide was added. The INR increased to 3.2 despite administration of fresh-frozen plasma and vitamin $\mathrm{K}$. The $\mathrm{Hb}$ fell to $6.5 \mathrm{~g} / \mathrm{dL}$, and packed red cells were transfused.

During day 3, urine output responded to treatment and the INR normalised with further vitamin $\mathrm{K}$ and plasma. On the evening of day 3, the patient developed respiratory distress because of severe swelling. An emergency tracheostomy was performed and a large haematoma was drained from the bite area. The CK peaked on day 2 at $75000 \mathrm{U} / \mathrm{L}$ and was $<500 \mathrm{U} / \mathrm{L}$ on day $8 . \mathrm{LDH}$ remained high until day 4 before starting to subside. Cumulative results are shown in Table 3.

The patient required several debridements for a large necrotic area on the scalp. Skin grafts were done by a plastic surgeon after 2 weeks. All parameters returned to normal and the patient was discharged after 3 weeks.

\section{Discussion}

Snake venom is highly modified saliva that contains a complex mixture of proteins, enzymes and other substances with toxic and lethal properties. Envenomation can produce neurotoxic, cytotoxic, haemotoxic, myotoxic and cardiotoxic symptoms, presenting as a single symptom complex or in any combination, depending on the composition of the venom. ${ }^{[18,19]}$

The majority of recorded bites by $N$. $n$. nigricincta were inflicted on the victim's extremities. The snake's fangs are relatively short $(\sim 3 \mathrm{~mm})$ with the venom opening proximal to the tip. ${ }^{[7]}$ One can speculate that in a bite on an extremity, the venom is usually injected into the subdermal layer between the skin and muscle. Owing to the low vascularity of this area, minimal or no systemic absorption occurs and only necrotising signs may develop. Bites on the face, directly intravascular or in cases of high venom-to-body ratio (e.g. babies and small children) will result in venom absorption into the circulation with systemic envenomation.

Intravascular haemolysis occurs from snake envenomation as a result of the action of phospholipase $\mathrm{A}_{2}$, which is present in almost all snake venoms, and a basic protein called direct lytic factor, found only in elapid venoms. ${ }^{[19]}$ With lysis of the red blood cells, haemoglobin is released into the bloodstream and is immediately bound by haptoglobin. ${ }^{[20]}$ If the haemolysis is beyond the reabsorptive capacity of the haptoglobin, excess haemoglobin is filtered by the kidney and results in haemoglobinurea and urine haemosiderin. ${ }^{[21]}$ Lysis of red cells causes anaemia ${ }^{[20]}$ and haem promotes neutrophil

Table 2. Laboratory results, patient 2

\begin{tabular}{|c|c|c|c|c|c|c|c|}
\hline Normal values & Day 1 & Day 2 & Day 3 & Day 4 & Day 5 & Day 6 & Day 7 \\
\hline $\mathrm{Hb}(11.5-15.5 \mathrm{~g} / \mathrm{dL})$ & 15.1 & 15.4 & 12.6 & 12.1 & 11.1 & 12.5 & 11.9 \\
\hline WBC $\left(4.5-13.5 \times 10^{9} / \mathrm{L}\right)$ & 31.4 & 28.8 & 19.3 & 16.6 & - & 11.9 & - \\
\hline Neutrophils $\left(1.5-8.5 \times 10^{9} / \mathrm{L}\right)$ & 25.4 & 24.7 & 15.4 & 13.5 & - & 9.27 & - \\
\hline $\operatorname{PLT}\left(140-420 \times 10^{9} / \mathrm{L}\right)$ & 433 & 391 & 329 & 368 & - & 445 & - \\
\hline INR $(0.9-1.3)$ & 1.5 & 1.8 & 1.4 & 1.0 & - & - & - \\
\hline PT $(10.2-13.2 s)$ & 16.1 & 19.3 & 15.3 & 12.2 & - & - & - \\
\hline PTT (25.4 - $38.4 \mathrm{~s})$ & 29.7 & 26.5 & - & - & - & - & - \\
\hline Unconjugated bilirubin $(2-17 \mu \mathrm{mol} / \mathrm{L})$ & 73 & 90 & 43 & - & - & - & - \\
\hline ALT $(0-55 \mathrm{U} / \mathrm{L})$ & 35 & 53 & 99 & - & - & - & - \\
\hline AST (5 - $34 \mathrm{U} / \mathrm{L})$ & 118 & 328 & 510 & - & - & - & - \\
\hline LDH (100 - $295 \mathrm{U} / \mathrm{L})$ & 793 & 1131 & 1364 & - & - & - & - \\
\hline CK $(30-200 \mathrm{U} / \mathrm{L})$ & 2090 & 8300 & 17360 & 11555 & 5430 & - & 609 \\
\hline
\end{tabular}


Table 3. Laboratory results, patient 3

\begin{tabular}{|c|c|c|c|c|c|c|c|c|c|}
\hline Normal values & Day 1 & Day 2 & Day 2 & Day 3 & Day 4 & Day 5 & Day 6 & Day 8 & Day 10 \\
\hline $\mathrm{Hb}(11.5-15.5 \mathrm{~g} / \mathrm{dL})$ & 9.6 & 6.4 & 8.5 & 10.5 & 10.2 & 12.0 & 10.8 & 10.9 & 9.6 \\
\hline WBC $\left(4.5-13.5 \times 10^{9} / \mathrm{L}\right)$ & 18.2 & 13.4 & 9.0 & 7.6 & 6.7 & 9.1 & 8.7 & 14.8 & 19.7 \\
\hline Neutrophils $\left(1.5-8.5 \times 10^{9} / \mathrm{L}\right)$ & 16.2 & 11.16 & 7.05 & 6.02 & 4.49 & 6.37 & 5.57 & 6.07 & 8.47 \\
\hline $\operatorname{PLT}\left(140-420 \times 10^{9} / \mathrm{L}\right)$ & 508 & 622 & 244 & 162 & 147 & 124 & 288 & 659 & 712 \\
\hline INR $(0.9-1.3)$ & 1.4 & 1.8 & 3.2 & 1.3 & 1.2 & 1.2 & - & 1.1 & 1.2 \\
\hline PT (10.2 - $13.2 \mathrm{~s})$ & 16.7 & 20.5 & 36.7 & 15.0 & 13.8 & 13.9 & - & 12.7 & 14.1 \\
\hline PTT (25.4 - $38.4 \mathrm{~s})$ & 78.6 & 36.8 & - & 19.6 & 33.5 & 39.7 & - & - & 30.3 \\
\hline Unconjugated bilirubin $(2-17 \mu \mathrm{mol} / \mathrm{L})$ & 15 & - & 28 & 36 & - & 12 & - & - & 3 \\
\hline $\operatorname{ALT}(0-55 \mathrm{U} / \mathrm{L})$ & 69 & - & 432 & 427 & - & 557 & - & - & 176 \\
\hline AST (5 - $34 \mathrm{U} / \mathrm{L})$ & 533 & - & 2212 & 1547 & - & 997 & - & - & 83 \\
\hline LDH (110 - $295 \mathrm{U} / \mathrm{L})$ & 1292 & - & 3055 & 2740 & - & 3049 & - & - & 1595 \\
\hline CK $(30-200 \mathrm{U} / \mathrm{L})$ & - & 35280 & 75700 & 43918 & - & - & - & 467 & - \\
\hline Serum myoglobin $(17-106 \mathrm{ng} / \mathrm{mL})$ & 11656 & - & 2211 & - & - & - & - & - & - \\
\hline Serum haptoglobin $(0.34-2.00 \mathrm{~g} / \mathrm{L})$ & $<0.06$ & - & 0.81 & - & - & - & - & - & - \\
\hline Urine myoglobin $(2.2-5.0 \mathrm{~g} / \mathrm{L})$ & - & + & - & - & - & - & - & - & - \\
\hline Fibrinogen & - & - & - & - & - & 4.5 & - & - & - \\
\hline
\end{tabular}

migration. Indicators of intravascular haemolysis are therefore low serum haptoglobin, haemoglobinuria, raised unconjugated bilirubin, falling haemoglobin values, markedly raised $\mathrm{LDH}$, leukocytosis and schistocytes. ${ }^{[22-24]}$

Rhabdomyolysis is a common consequence of snake envenomation. Myotoxic phospholipases $A_{2}$ in the venom bind to acceptors in the plasma membrane, initiating a series of complex degenerative events culminating in the dispersion of muscle constituents into the circulation. ${ }^{[25,26]}$ Large quantities of potassium, phosphate, myoglobin, aldolase, CK, LDH, AST and purines leak into the circulation. Myoglobin in the renal filtrate can cause renal tubular damage by several mechanisms. ${ }^{[22,25,27-29]}$ Proteases released from muscle injury cause hepatic dysfunction. ${ }^{[30]}$ Hyperkalaemia, hypocalcaemia and hepatic inflammation are early complications, late complications being renal failure and diffuse intravascular coagulation probably caused by the activation of the clotting cascade by components released from the damaged muscles. ${ }^{[25,29]}$

Our patients exhibited leukocytosis, very high CK values (peaking 2 - 3 days after the bite), raised serum myoglobin, low serum haptoglobin, raised AST, ALT and LDH, and an increased INR. Patient 3 also exhibited polychromasia, burr cells and aniso-poikilocytosis on peripheral blood smears. A decrease in Hb was common.

A definitive diagnosis of rhabdomyolysis was made on the grounds of the serum CK being more than five times the normal value, and the presence of urine or serum myoglobin. The decrease in $\mathrm{Hb}$, leukocytosis and peripheral smear features are more specific for haemolysis. Increased AST, LDH and unconjugated bilirubin, low serum haptoglobin and positive urine dipstick for blood overlap for both intravascular haemolysis and rhabdomyolysis. ${ }^{[21-23,25-36]}$

These rhabdomyolytic and intravascular haemolytic effects of $N$. $n$. nigricinta venom have not been recorded previously. ${ }^{[31]}$ A recent study by Bittenbinder et al ${ }^{[32]}$ demonstrated inhibition of both factor Xa and thrombin by the venom of N. n. nigricinta. Whether the transient rise in the INR was the result of the direct toxic effects of the venom on the clotting cascade, or of disseminated intervascular coagulation secondary to rhabdomyolysis, needs further research. ${ }^{[22,33]}$
Additionally, the drowsiness and convulsion seen in our two younger patients may reflect neurotoxic symptoms due to the high venom-tomass ratio in smaller victims. ${ }^{[37]}$

Although the toxic composition of snake venom varies between species and even within the same species, ${ }^{[18,19,27]}$ we hope that publishing these case studies will rekindle interest in and awareness of the systemic effects of envenomation by African spitting cobras, resulting in species-specific research.

\section{Declaration. None.}

Acknowledgements. We thank Dr Carel Haumann for his assistance with clinical pathology.

Author contributions. ELS wrote the manuscript. PJCB advised, oversaw and supervised the research and compilation of the manuscript.

Funding. None.

Conflicts of interest. None.

1. Global snakebite initiative. http://www.snakebiteinitiative.org/ (accessed 26 June 2017)

2. World Population Review. Namibia population 2019 (demographs, maps, graphs). 2019. http:// worldpopulationreview.com/countries/namibia-population/ (accessed 30 March 2019).

Worldpopulationreview.com/countries/namibia-population/ (accessed 30 March 2019 ).
3. Buys PJ, Buys PJC. Slange van Suidwes-Afrika. 1st ed. Windhoek: Gamsberg, 1983.

3. Buys PJ, Buys PJC. Slange van Suidwes-Afrika. 1st ed. Windhoek: Gamsberg, 1983.
4. Griffen M. The zebra snake antivenom project. Travel News Namibia. 2001. http://www.travelnewsnamibia. $\mathrm{com} /$ stories/featured-stories/the-zebra-snake-antivenom-project/ (accessed 9 August 2017).

5. Panagides N, Jackson TNW, Ikonomopoulou MP, et al. How the cobra got its flesh-eating venom: Cytotoxicity as a defensive innovation and its co-evolution with hooding, aposematic marking, and spitting. Toxins 2017;9(3):103. https://doi.org/10.3390/toxins 9030103

6. Warrell DA, Greenwood BM, Davidson NMCD, Ormerod LD, Prentice CRM. Necrosis, haemorrhage and complement depletion following bites by the spitting cobra (Naja nigricollis). Q J Med 1976;45(177):1-22. https://doi.org/10.1093/oxfordjournals.qjmed.a067448

7. Tilbury CR. Observations on the bite of the Mozambique spitting cobra (Naja mossambica mossambica). S Afr Med J 1982;61(9):308-313.

8. Vermaak SS, Visser A, le Roux TLB. A deadly bed partner: m'Fesi (Mozambique spitting cobra). S Afr Orthop J 2010;9(4):58-62. http://www.scielo.org.za/scielo.php?script=sci_arttext\&pid=S1681150X2010000400011 (accessed 6 September 2019).

9. Marais J. A Complete Guide to the Snakes of Southern Africa. 2nd ed. Cape Town: Struik, 2004.

9. Marais J. A Complete Guide to the Snakes of Southern Africa. 2nd ed. Cape Town: Struik, 2004.
10. South African Institute for Medical Research. Anti-Snakebite Serum. (Package Insert with Antivenom), 2006. . South African Institute for Medical Research. Anti-Snakebite Serum.(Package Insert with Antivenom),2006.
http://www.toxinfo.org/antivenoms/resources/antivenom_southafrica-savp-polyvalentsnake_2011-07-04. pdf (accessed 6 September 2019)

11. Rademeyer R. Sebraslang se byt laat man kritiek. Republikein, 13 January 2000.

12. Isaacs D. Snakebite doctor acquitted. The Namibian, 17 February 2009.

13. Esmaeilishirazifard E, Usher L, Trim C, et al. Microbial adaptation to venom is common in snakes and spiders. bioRxiv 2018. https://doi.org/10.1101/348433

14. Garg A, Sujatha S, Garg J, Acharya NS, Parija SC. Wound infections secondary to snakebite. J Infect Dev Ctries 2009;3:221-223. https://doi.org/10.3855/jidc.39 
15. Shek KC, Tsui KL, Lam KK, et al. Oral bacterial flora of the Chinese cobra (Naja atra) and bamboo pit viper (Trimeresurus albolabris) in Hong Kong SAR, China. Hong Kong Med J 2009;15(3):183-190. pit viper (Trimeresurus albolabris) in Hong Kong
https://www.ncbi.nlm.nih.gov/pubmed/19494373b.

16. Blaylock RS. Antibiotic use and infection in snakebite victims. S Afr Med J 1999;89(8):974-876.

17. Wagener M, Naidoo M, Aldous C. Wound infection secondary to snakebite. S Afr Med J 2017;107(4):315319. https://doi.org/10.7196/SAMJ.2017.v107i4.12084

18. Wikipedia. Snake venom. https://en.wikipedia.org/wiki/Snake_venom (accessed 23 January 2017).

19. Casewell NR, Wagstaff SC, Wuster W, et al. Medically important differences in snake venom composition are dictated by distinct postgenomic mechanisms. Proc Natl Acad Sci U S A 2014;111(25):9205-9210. https://doi.org/10.1073/pnas.1405484111

20. USMLE Forums. Intravascular versus extravascular hemolysis. https://www.usmle-forums.com/usmlestep-1-bits-pieces/324-intravascular-versus-extravascular-hemolysis.html (accessed 13 June 2016).

21. Barcellini W, Fattizzo B. Clinical applications of hemolytic markers in the differential diagno and management of hemolytic anemia. Dis Markers 2015, Article ID 635670. https://doi. org $/ 10.1155 / 2015 / 635670$

22. Nader ND. Neutrophilia. Medscape. 29 December 2015. https://emedicine.medscape.com/ article/208576-overview\#a2 (accessed 25 June 2016).

23. Graça-Souza AV, Arruda MAB, de Freitas MS, Barja-Fidalgo C, Oliveira PL. Neutrophil activation by heme: Implications for inflammatory processes. Blood 2002;99:4160-4165. https://doi.org/10.1182/ blood.V99.11.4160

24. Schick P. Hemolytic anaemia workup. Medscape. 2017. http://emedicine.medscape.com/article/201066workup (accessed 24 April 2018)

25. Sauret JM, Marinides G, Wang GK. Rhabdomyolysis. Am Fam Physician 2002;65(5):907-913. https:// www.aafp.org/afp/2002/0301/p907.html

26. De Guzman MM, Jung LK. Rhabdomyolysis, Medscape. 14 Oct 2018. https://emedicine.medscape.com/ article/1007814-overview

27. Gutiérrez JM, Ownby CL. Skeletal muscle degeneration induced by venom phospholipases $\mathrm{A}_{2}$ : Insights into the mechanisms of local and systemic myotoxicity. Toxicon 2003;42(8):915-931. https://doi. org/10.1016/j.toxicon.2003.11.005
28. Hunter ID, Gregg K, Damani Z. Rhabdomyolysis. Contin Educ Anaesth Crit Care Pain 2006;6(4):141143. https://doi.org/10.1093/bjaceaccp/mkl027

29. Bhagwat K, Amar L. Blood hemoglobin, lactate dehydrogenase and total creatine kinase combinely as markers of hemolysis and rhabdomyolysis associated with snake bite. Int J Toxicol Pharmacol Res 2013;5(1):5-8.

30. Wheby MS, Barrett OC, Crosby WH. Serum protein binding of myoglobin, hemoglobin and hematin Blood 1960;16(5):1579-1585. http://www.bloodjournal.org/content/16/5/1579?sso-checked=true (accessed 3 September 2019).

1. Sitprija V, Gopalakrishnakone P. Snake bite, rhabdomyolysis, and renal failure. Am J Kidney D 1998;31(6):I-Iiii. https://doi.org/10.1016/S0272-6386(14)70010-1

32. Bittenbinder MA, Zdenek CN, Op den Brouw B, et al. Coagulotoxic cobras: Clinical implications of strong anticoagulant actions of African spitting Naja venoms that are not neutralised by antivenom but are by LY315920 (varespladib). Toxins 2018;10(12):516. https://doi.org/10.3390/toxins10120516

33. White J. Snake venoms and coagulopathy. Toxicon 2005;45(8):951-967. https://doi.org/10.1016/j. toxicon.2005.02.030

34. Huerta-Alardin AL, Varon J, Marik PE. Bench-to-bedside review: Rhabdomyolysis - an overview for clinicians. Crit Care 2004;9:158. https://doi.org/10.1186/cc2978

35. Keltz E, Khan FY, Mann G. Rhabdomyolysis: The role of diagnostic and prognostic factors. Muscles . Keltz E, Khan FY, Mann G. Rhabdomyolysis: The role of diagnostic and progn
Ligaments Tendons J 2013;3(4):303-312. https://doi.org/10.32098/mlti.04.2013.11

36. Ligaments Thand. Rhabdomyolysis. Department of Anaesthesia \& Intensive Care, Chinese University of Hon Kong. 2006. https://www.aic.cuhk.edu.hk/web8/rhabdomyolysis.htm (accessed 3 September 2019).
Ko

37. Ranawaka UK, Lalloo DG, de Silva HJ. Neurotoxicity in snakebite - the limits of our knowledge. PLoS Negl Trop Dis 2013;7(10):e2302. https://doi.org/10.1371/journal.pntd.0002302 